\title{
Maxillomandibular Vascular Malformations: Report of Four Cases
}

\author{
Krishnan Nagarajan ${ }^{1}$ Mohan Amuthabarathi ${ }^{1} \quad$ Balasubramanian Krishnan ${ }^{2} \quad$ Sekar Sabarish ${ }^{1}$ \\ Rajendiran Saravanan ${ }^{2}$
}

1Department of Radio-Diagnosis, Jawaharlal Institute of Postgraduate Medical Education \& Research, Pondicherry, India

${ }^{2}$ Department of Dentistry, Jawaharlal Institute of Postgraduate

Medical Education \& Research, Pondicherry, India

\begin{abstract}
Address for correspondence Krishnan Nagarajan, MD, DM, Department of Radio-Diagnosis, Jawaharlal Institute of Postgraduate Medical Education and Research, Pondicherry 605006, India (e-mail: Iknagarajan1@gmail.com).
\end{abstract}

\begin{abstract}
Keywords

- arteriovenous malformations

- maxillomandibular AVMs

- dental arcade AVMs

- CT angiography

- digital subtraction angiography

- embolization

Maxillomandibular or dental arcade arteriovenous malformations (AVMs) are uncommon lesions with potential for life-threatening bleeding. We report three cases of vascular malformations and a case of pyogenic granuloma and propose a contrast-enhanced computed tomography (CT)-based workup of these lesions for definitive treatment. Four cases of orodental bleeding were diagnosed based on CT angiography (CTA) and treated using endovascular means. Three of them were subsequently operated and confirmed by histopathology. Two were low-flow AVMs, the third one a case of pyogenic granuloma, and one high-flow AVM. The first three lesions were embolized with polyvinyl alcohol particles and subsequently operated and the fourth high-flow one embolized using liquid embolic agent $n$-butyl cyanoacrylate (Glue). CTA can be used to show separate lesions of arterial vascularity and those of delayed/ venous enhancing lesions. Arterial phase-enhancing lesions are again subdivided in digital subtraction angiography into those of low-to-moderate vascularity and those with high flow, which are treated using particle embolization and liquid glue/onyx ( \pm coil) embolization, respectively. The delayed venous phase enhancing lesions may mimic neoplasms and after tissue biopsy may be managed by sclerotherapy.
\end{abstract}

\section{Introduction}

Arteriovenous malformations (AVMs) of the jaws are relatively uncommon. ${ }^{1}$ They may not be obvious at birth and can grow with the child. ${ }^{2} \mathrm{~A}$ few cases have been reported to be of posttraumatic origin. ${ }^{3}$ They may have low-to-moderate flow or high fistulous flow and can present with symptoms such as facial swelling, loosening of the tooth, gingival bleeding, and sometimes with life-threatening hemorrhage, especially after dental extraction. The treatment has been one of resection, curettage, embolization, sclerotherapy, and even radiotherapy. Currently, endovascular embolization is

published online May 17, 2021
DOI https://doi.org/

$10.1055 / \mathrm{s}-0041-1728997$ ISSN 2457-0214 considered the first line of treatment, usually transarterial or intranidal/-osseous embolization using particles, liquid embolic agents, or coils. ${ }^{4}$ Complete obliteration may be difficult in high-flow, complex lesions, which may need multiple sittings and occasionally direct puncture of the intraosseous pouch to improve the outcome. ${ }^{5}$

\section{Case Report}

\section{Case 1}

A 15-year-old boy presented with swelling of the left lower jaw for 1 month, which started as small swelling and then
(C) 2021. Indian Society of Vascular and Interventional Radiology. This is an open access article published by Thieme under the terms of the Creative Commons Attribution-NonDerivative-NonCommercial-License, permitting copying and reproduction so long as the original work is given appropriate credit. Contents may not be used for commercial purposes, or adapted, remixed, transformed or built upon. (https://creativecommons.org/licenses/by-nc-nd/4.0/). Thieme Medical and Scientific Publishers Pvt. Ltd. A-12, 2nd Floor, Sector 2, Noida-201301 UP, India 
ulcerated. There was no associated fever or pain. An ulcerated swelling was noted intraorally over the left side of the body of mandible around the premolars. There were clots around the gingival sulcus of involved teeth. Orthopantomogram (OPG) showed a mixed radiopaque-lucent lesion in the left anterior paramedian mandible with ill-defined margins. Contrast-enhanced CT (CECT) showed an expansile lytic lesion in the left body of mandible around the incisorcanine roots, with enhancing septations in the arterial phase probably from the left lingual artery. Cortical breaks of the mandible in both lingual and buccal aspects were noted. Digital subtraction angiography (DSA) showed a moderate-flow AVM involving the left paramedian mandible near the incisor-canine root region fed by the left lingual artery with few early draining veins ( - Fig. 1). The lingual branch was selectively catheterized using a microcatheter (Progreat, Terumo) and embolized using polyvinyl alcohol (PVA) $(150-250 \mu \mathrm{m})$ particles in saline-contrast mixture. Post-procedure check angiogram showed near-complete reduction in abnormal vascularity and blush. The swollen lesion was excised and showed thrombosed vascular malformation.

\section{Case 2}

A 55-year-old female came with oral bleeding for 1 month. She gave a history of jaw swelling for 1 year. Oral examination showed a smooth swelling in anterior mandibular symphysis involving the alveolar processes of incisors and canine. There was no extension to the floor of the mouth or labial vestibule. OPG showed similar radiopaque-radiolucent lesion in the anterior mandible with ill-defined margins. There was root resorption within the lesion and pathological migration apart from generalized horizontal bone loss, multiple grossly destructed teeth, and root stumps. CECT showed enhancing soft tissue lesion anterior to mandibular symphysis with arterial and delayed phase enhancement probably from the facial artery branches. DSA showed moderate-flow vascular malformation fed by dilated labial branches from bilateral facial arteries with abnormal blush in the mandibular region ( - Fig. 2). However, no early draining veins were seen. Labial branches were superselectively catheterized and embolized with PVA (250-350 $\mu \mathrm{m})$ particles in saline-contrast mixture. Post-procedure angiogram showed near-total reduction in abnormal blush. The lesion was excised lesion and histopathology showed features of vascular malformation.

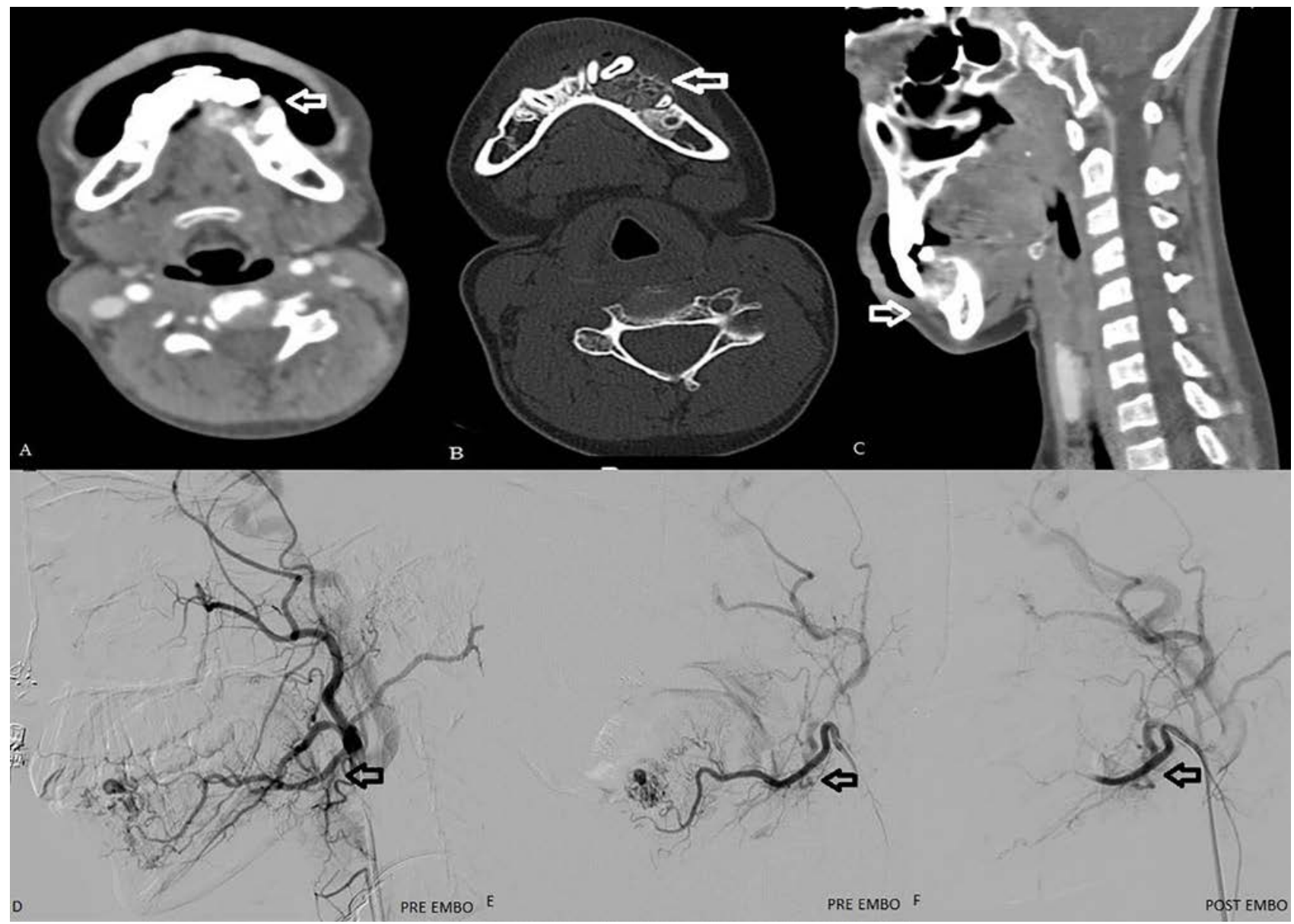

Fig. 1 Axial (A), bone window (B), and sagittal reformatted (C) computed tomographic images showed an expansile lytic lesion with septations in the left side of the body of mandible around the alveolus of canine to premolars region (arrow). (D, E) External carotid artery (ECA) angiogram lateral view showed an arteriovenous malformation in the left side of the mandible near the canine root region fed by left lingual artery branches (arrow). (F) ECA post-procedure check angiogram lateral view revealed complete obliteration of the nidus (arrow). 

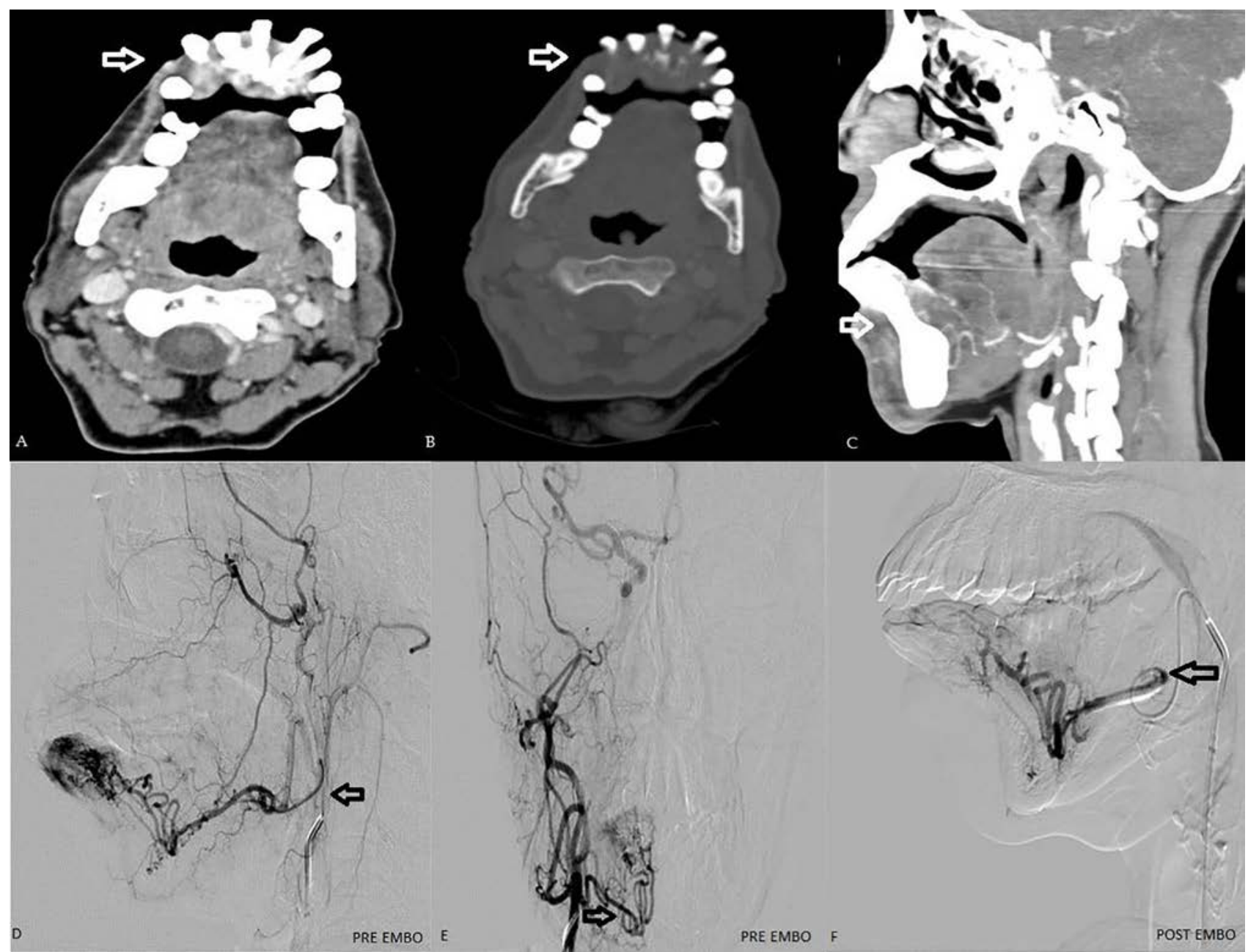

Fig. 2 Axial (A), bone window (B), and sagittal reformatted (C) computed tomography images showed a lytic lesion with enhancing soft tissue component in anterior mandibular symphysis (arrow). (D, E) External carotid artery (ECA) angiogram lateral and anteroposterior view showed an arteriovenous malformation in the anterior mandible symphysis region fed by right facial artery branches (arrow). (F) ECA post-procedure check angiogram lateral view revealed complete obliteration of the nidus.

\section{Case 3}

A 6-year-old boy had episodes of spontaneous bleeding from gum. There was facial asymmetry with erythema over the right maxillary and forehead region. Gingival swelling was noted in the right buccal and palatine region of the maxilla. CT done outside showed sclerotic lesion involving the right maxilla with enhancement in arterial phase. Magnetic resonance imaging (MRI) showed T2-weighted hyperintense expansile lesion in the right maxilla involving the alveolar process with postcontrast enhancement. Possibility of a vascular lesion like hemangioma was suspected and DSA was done that showed abnormal blush in the right maxillary region fed by the descending palatine branch of right internal maxillary artery (-Fig. 3). The descending palatine branch was superselectively catheterized and embolized with PVA (250-350 $\mu \mathrm{m})$ particles in saline-contrast mixture. The lesion was excised with adjacent part of the maxillary bone and the histopathological diagnosis was that of pyogenic granuloma.

\section{Case 4}

A 5-year-old girl presented with spontaneous gum bleeding for 2 months, which had increased to more than $200 \mathrm{~mL}$ the previous day. On examination, pulsatile swelling was noted on the right lower gum with erosion of root of the teeth and adjacent buccal cortex. CECT showed intensely enhancing lesion in the body of the right mandible involving the alveolar process with arterial feeders from the lingual artery and the inferior alveolar branch of maxillary artery. The intraosseous component was a large dilated venous sac with erosion of the body of the mandible (-Fig. 4). DSA showed nidus along the condyle and ramus of the mandible fed by the lingual artery and inferior alveolar branch of internal maxillary artery with an abnormal blush of intranidal/venous sac in the right mandibular region (-Fig. 4). The inferior alveolar branch and the lingual branch were superselectively catheterized and embolized with 33 and 50\% n-butyl cyanoacrylate ( $n \mathrm{BCA}$ )-lipiodol mixture, respectively. Post-procedure check angiogram showed near-total reduction (> 95\%) in abnormal vascularity and blush. She is on follow-up. 


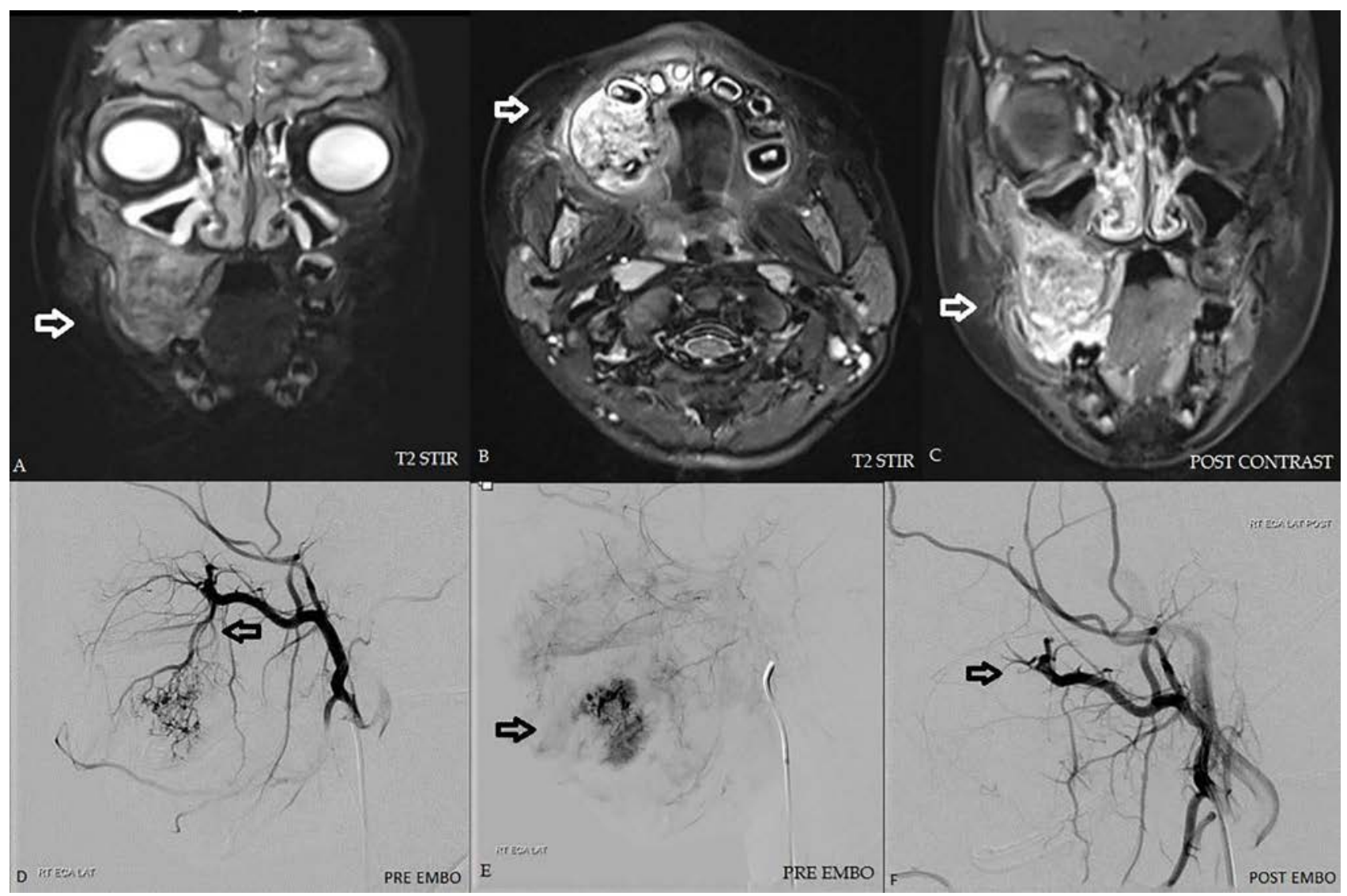

Fig. 3 (A) Coronal and (B) axial T2 short tau inversion recovery magnetic resonance imaging images showed a hyperintense expansile lesion in the right maxilla involving the alveolar process. (C) Post-contrast T1-weighted coronal images showed heterogeneously enhancing lesion in the right maxilla involving the alveolar process (arrow). (D, E) External carotid artery (ECA) angiogram lateral view showing abnormal blush in right maxillary region fed by right internal maxillary artery branch (descending palatine artery) (arrow). (F) ECA post-procedure check angiogram lateral view revealed near-total reduction in abnormal blush (arrow).

The clinical and DSA findings of all four patients are summarized in - Table 1 .

\section{Discussion}

AVMs of the jaw usually present in the second decade and the molar region are commonly involved through which the inferior alveolar and superior posterior alveolar vascular bundle traverse. ${ }^{6}$ Various triggering factors of these lesions include endocrine or hormonal factors (puberty and pregnancy), trauma, iatrogenic (biopsy, incomplete surgery, and proximal embolization) and infection. ${ }^{7}$ The radiographic appearance is nonspecific with a honeycomb or soap-bubble lesion, alveolar erosion, and root resorption leading to a "floating tooth" appearance. On CT, they appear as lytic lesions with sclerotic reactions. MRI shows heterogeneous soft tissue lesion with T2/STIR hyperintensities and contrast enhancement. Serpiginous signal voids may be seen in high-flow lesions. Phleboliths representing calcified thrombi are usually seen in venous malformations without arterial flow. ${ }^{8}$

DSA is done in bilateral external carotid artery (ECA) and internal carotid artery (ICA) and occasionally the vertebral arteries. ECA is assessed for arterial feeders, venous drainage, and the intraosseous components apart from any dangerous anastomosis with ICA that can have implications during embolization. The arterial feeders depend on the location of the malformation-whether maxillary or mandibular, incisor-canine, or molar region-and are from labial and submental branches from the faciolingual trunk, labial, or masseteric branch of internal maxillary, etc. The draining veins usually are the posterior facial vein for mandibular lesions and the pterygoid plexus for maxillary lesions. Those with cheek involvement may also show drainage through the angular or ophthalmic veins to the cavernous sinus. ${ }^{10}$

The choice of the embolic agent depends on the type of vascularity and flow characteristics. In moderate flow lesions with nidus, particles like gel foam or PVA are used. ${ }^{10}$ Microcatheter particle injection is carefully done to reach smaller vessels in the nidus avoiding reflux or proximal occlusion that can risk adjacent normal tissue and incomplete target embolization, though risk to adjacent soft tissue is minimal due to extensive collaterals in maxillofacial blood supply. ${ }^{8,9}$ High-flow lesions with fistula need coils to reduce the flow followed by liquid embolic agent and, those without fistula may be treated using liquid embolic agent for complete obliteration of the intraosseous nidus and sac. ${ }^{7}$

Churojana et $\mathrm{al}^{7}$ described series of 93 facial AVMs treated over a period of 18 years using endovascular means and found 5 maxillomandibular AVMs with uncontrolled dental bleeding. Four patients underwent arterial feeder 


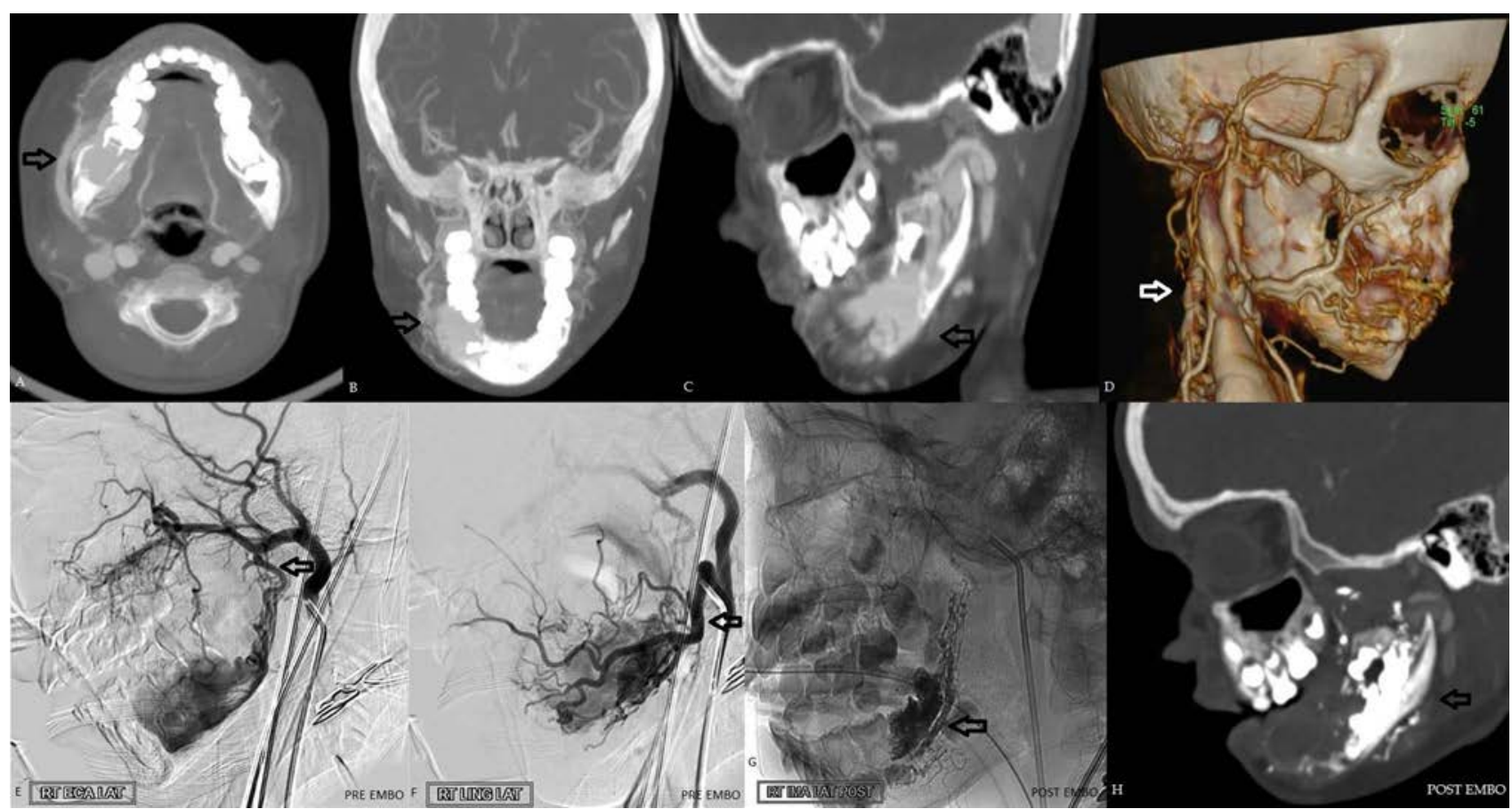

Fig. 4 Axial (A), coronal (B), and sagittal (C) reformatted and volume rendered (D) computed tomography (CT) images showed an intensely enhancing lesion in the body of the right mandible involving the alveolar process (arrow) with arterial feeders from the lingual artery and inferior alveolar branch of the maxillary artery. (E, F) External carotid artery angiogram lateral view showed a high flow arteriovenous malformation in the body of the right mandible with feeders from the inferior alveolar branch of the maxillary artery and lingual artery (arrow). Post-embolization check tomography $(\mathbf{G})$ and sagittal reformatted CT $(\mathbf{H})$ revealed glue cast in the body of the right mandible (arrow).

Table 1 Clinical, CT, DSA findings, and interventional treatment in four cases

\begin{tabular}{|c|c|c|c|c|c|c|}
\hline $\begin{array}{l}\text { S. } \\
\text { No. }\end{array}$ & $\begin{array}{l}\text { Age/ } \\
\text { gender }\end{array}$ & Clinical findings/location & CT & DSA & Embolization & Histopathology \\
\hline 1. & $15 / M$ & $\begin{array}{l}\text { Ulcerated swelling over } \\
\text { the left side of the body } \\
\text { of mandible around the } \\
\text { alveolus of premolars }\end{array}$ & $\begin{array}{l}\text { Expansile lytic lesion in } \\
\text { the left side of a body } \\
\text { of mandible around the } \\
\text { alveolus of premolars } \\
\text { with intensely enhancing } \\
\text { septations in the arterial } \\
\text { phase }\end{array}$ & $\begin{array}{l}\text { Left lingual art } \\
\text { feeder }\end{array}$ & $\begin{array}{l}\text { PVA particles } \\
(150-250 \mu \mathrm{m})\end{array}$ & $\begin{array}{l}\text { Arteriovenous } \\
\text { malformation }\end{array}$ \\
\hline 2. & $55 / F$ & $\begin{array}{l}\text { Swelling in anterior mandib- } \\
\text { ular symphysis in alveolar } \\
\text { processes of incisors and } \\
\text { canine }\end{array}$ & $\begin{array}{l}\text { Enhancing soft tissue } \\
\text { lesion in a subcutane- } \\
\text { ous plane anterior to } \\
\text { mandibular symphysis } \\
\text { with arterial and delayed } \\
\text { phase enhancement. }\end{array}$ & $\begin{array}{l}\text { Bilateral facial } \\
\text { art (labial } \\
\text { branches) }\end{array}$ & $\begin{array}{l}\text { PVA particles } \\
(250-350 \mu \mathrm{m})\end{array}$ & $\begin{array}{l}\text { Arteriovenous } \\
\text { malformation }\end{array}$ \\
\hline 4. & $6 / M$ & $\begin{array}{l}\text { Pedunculated gingival } \\
\text { swelling in right buccal } \\
\text { and palatine region of the } \\
\text { maxilla }\end{array}$ & $\begin{array}{l}\text { MRI-heterogeneously } \\
\text { enhancing T2 hyperin- } \\
\text { tense expansile lesion in } \\
\text { the right maxilla involv- } \\
\text { ing the alveolar process }\end{array}$ & $\begin{array}{l}\text { Right inter- } \\
\text { nal maxillary } \\
\text { (descending } \\
\text { palatine branch) }\end{array}$ & $\begin{array}{l}\text { PVA particles } \\
(250-350 \mu \mathrm{m})\end{array}$ & Pyogenic granuloma \\
\hline 5. & $5 / F$ & $\begin{array}{l}\text { Pulsatile swelling on right } \\
\text { lower gum with erosion of } \\
\text { root of the teeth }\end{array}$ & $\begin{array}{l}\text { Intensely enhancing } \\
\text { lesion involving the } \\
\text { alveolar process of body } \\
\text { of right mandible with a } \\
\text { large dilated venous sac } \\
\text { with erosion }\end{array}$ & $\begin{array}{l}\text { Lingual artery } \\
\text { and infer alve- } \\
\text { olar art from } \\
\text { intern maxillary } \\
\text { art }\end{array}$ & Glue & $\begin{array}{l}\text { Not operated, on } \\
\text { follow-up }\end{array}$ \\
\hline
\end{tabular}

Abbreviations: CT, computed tomography; DSA, digital subtraction angiography; MRI, magnetic resonance imaging; PVA, polyvinyl alcohol.

embolization using the glue-lipiodol mixture and direct transosseous puncture of the venous sac with glue was done in one patient. Saraf et $\mathrm{al}^{4}$ reported six maxillomandibular AVMs in which five were in the mandible and one in the maxilla. Glue and onyx were used in three patients each, with additional intraosseous injection in one patient of each group. Transarterial onyx was used in two patients using dual lumen balloon catheter to prevent reflux of onyx. Rodesch 
et $\mathrm{al}^{10}$ described 12 dental arcades AVM over a period of 20 years, of which 7 were mandibular and 5 maxillary. Nine patients were treated with PVA particle embolization, but follow-up glue-embolization or surgery was needed in five due to recurrences. Glue ( $n \mathrm{BCA}$ ) was used in eight patients, out of which three had primary glue embolization, and five in those who had prior PVA embolization. Direct transcutaneous puncture was used in four patients. Parihar et $\mathrm{al}^{11}$ in their report of intraosseous maxillary AVM used direct sac injection of glue causing embolization of nidus and initial segment of venous outflow. Loureiro et al ${ }^{12}$ described endovascular glue embolization of mandibular AVM initially mistaken as keratocystic lesion and treated by transarterial embolization and direct transosseous puncture of the venous sac. Liu et $\mathrm{al}^{5}$ described eight patients having central AVMs of the jaw ( 3 maxillary and 5 mandibular) and treated using intraosseous glue-lipiodol injection along with venous compression.

Liu et a ${ }^{13}$ classified the central AVMs in the jaw based on radiographic and angiographic features into five types for planning the treatment. They are type I-AVMs of diffuse micro-AV fistulas with multiple arterial feeders and draining veins were treated by combined super-selective arterial embolization and complete curettage; type II and III with single venous pouch were treated with complete venous occlusion aided by arterial embolization; type IV and V with multiple venous pouches were managed by arterial and venous embolization followed by curettage.

Our last case had a large intranidal/venous pouch that presented with potentially life-threatening bleeding and was managed using transarterial glue embolization due to high-arterial flow. Direct intraosseous puncture and glue embolization of large intranidal/venous sac are useful in selected cases where arterial feeders are small or inaccessible, in previous surgical ligation or proximal feeder occlusion making endovascular approach unfeasible, or to obliterate a big venous pouch completely in one sitting. ${ }^{7}$ Though venous outlet compression has been used in direct puncture, it may not be always feasible in deeper draining veins.

The cause for large intraosseous sac in high-flow AVMs is not known but may be related to the neurovascular bundle going through the medulla of the jaw bones. ${ }^{9}$ The intraosseous dilation of the inferior alveolar vein and the posterior superior alveolar vein is thought to give rise to varix formation seen on the arteriogram.

Our third case proved to be pyogenic granuloma in postresection histopathology. Also known as lobular capillary hemangiomas, pyogenic granulomas have fibrovascular elements and can resemble low-to-moderate flow malformation in CTA and DSA and hence managed in similar way. ${ }^{14}$

The reported minor complications of embolization are facial pain or numbness, headache, trismus, and complications related to femoral artery cannulation, such as groin pain or hematoma. Another complication is delayed mucosa dehiscence, due to exposure to the glue cast. ${ }^{7}$ Antibiotics and anti-inflammatory medication are given after embolization treatment to avoid infection or local inflammatory reaction (causing trismus), which may be slightly more with the direct puncture. Tooth extraction is discussed in each case, especially if one presents with deciduous teeth. The pathological tooth represents a trigger factor to further trauma that may result in further bleeding and it may have to be removed to suppress this potential source. ${ }^{10}$

Endovascular techniques cure the lesion or stabilize them it without affecting the morphology of the facial skeleton enabling future proper ossification of the venous pouches. As these lesions often present in childhood, it is imperative to preserve the growth potential of the maxillofacial bones.

\section{Conflict of Interest}

None declared.

\section{References}

1 Remonda L, Schroth G, Ozdoba C, Lövblad K, Lädrach K, Huber P. Facial intraosseous arteriovenous malformations: CT and MR features. J Comput Assist Tomogr 1995;19(2):277-281

2 Sadove AM, Eppley BL, Gossweiler K, Hathaway R. Mandibular vascular malformations: treatment and long-term results. J Craniofac Surg 1994;5(5):289-294

3 Kennedy KS. Arteriovenous malformation of the maxilla. Head Neck 1990;12(6):512-515

4 Saraf R, Shrivastava M, Siddhartha W, Limaye U. Dental arcade arteriovenous fistulas: from diagnosis to treatment with emphasis on the role of endovascular or percutaneous treatment: single centre experience. J Craniomaxillofac Surg 2014;42(7):1480-1485

5 Liu D, Ma X, Zhao F, Zhang J. Intraosseous embolotherapy of central arteriovenous malformations in the jaw: long-term experience with 8 cases. J Oral Maxillofac Surg 2009;67(11):2380-2387

6 Shapiro NL, Cunningham MJ, Bhattacharyya N, Choi IS, Pile-Spellman J, Joseph MP. Osseous craniofacial arteriovenous malformations in the pediatric population. Arch Otolaryngol Head Neck Surg 1997;123(1):101-105

7 Churojana A, Khumtong R, Songsaeng D, Chongkolwatana C, Suthipongchai S. Life-threatening arteriovenous malformation of the maxillomandibular region and treatment outcomes. Interv Neuroradiol 2012;18(1):49-59

8 Persky MS, Yoo HJ, Berenstein A. Management of vascular malformations of the mandible and maxilla. Laryngoscope 2003;113(11):1885-1892

9 Fan X, Qiu W, Zhang Z, Mao Q. Comparative study of clinical manifestation, plain-film radiography, and computed tomographic scan in arteriovenous malformations of the jaws. Oral Surg Oral Med Oral Pathol Oral Radiol Endod 2002;94(4):503-509

10 Rodesch G, Soupre V, Vazquez MP, Alvarez H, Lasjaunias P. Arteriovenous malformations of the dental arcades. The place of endovascular therapy: results in 12 cases are presented. J Craniomaxillofac Surg 1998;26(5):306-313

11 Parihar A, Tomar S, Phadke RV. Direct sac puncture and glue embolization of intraosseous AVM of the maxilla. Int J Oral Maxillofac Surg 2011;40(7):749-752

12 Loureiro CC, Falchet PC, Gavranich J Jr, Lobo Leandro LF. Embolization as the treatment for a life-threatening mandibular arteriovenous malformation. J Craniofac Surg 2010;21(2):380-382

13 Liu DG, Ma XC, Zhao FY, Zhang JG. A preliminary study of angiographic classification and its correlation to treatment of central arteriovenous malformation in the jaw. Oral Surg Oral Med Oral Pathol Oral Radiol Endod 2005;100(4):473-480

14 Choudhary S, MacKinnon CA, Morrissey GP, Tan ST. A case of giant nasal pyogenic granuloma gravidarum. J Craniofac Surg 2005;16(2):319-321 